\title{
Octreotide Decreases Biliary and Pancreatic Exocrine Function, and Induces Steatorrhea in Healthy Subjects
}

\author{
Teruo NaKamura, Kenji Kudoh, Kazuo Takebe, Ken-ichi Imamura, Akinori Terada, \\ Hiroaki KIKUCHI, Naoko YamadA, Yuki AraI, Yusuke TANDO, Koji MachidA and Masataka IshII
}

A somatostatin analogue (SMS-201-995, hereinafter "octreotide") was s.c. administered to 5 healthy subjects under consecutive dripping of CCK-PZ (cholecystokinin-pancreozymin) and secretin (0.01 CHR U/kg/minutes), after inserting a Dreiling double tube into Treitz's ligament. Bile acid concentration, and bicarbonate and lipase excretions in duodenal juice were determined every 10 minutes up to 120 minutes and compared with controls. Moreover, octreotide $(100 \mu \mathrm{g})$ was s.c. administered to 5 healthy subjects 30 minutes before meals for $\mathbf{7}$ days. Fecal fat and bile acid excretions before and after administration were determined. Bile acid concentration, and bicarbonate and lipase excretions in the octreotide group decreased to 1/3-1/4 that of controls. Bile acid concentration became $0 \mathrm{mM}$ for 60 minutes. Fecal fat excretion increased; obvious steatorrhea occurred in 2 cases. Fecal bile acid excretion decreased to about 1/4. These results suggest that decreases in bile acid secretion should be considered, as well as pancreatic lipase and bicarbonate secretions, when fatty stool occurs after octreotide administration.

(Internal Medicine 33: 593-596, 1994)

Key words: pancreozymin-secretin, biliary inhibition, inhibition of bicarbonate and lipase, somatostatin analogue, greasy stool

\section{Introduction}

Somatostatin is present in the stomach, small intestine, pancreas, etc. and exerts its physiological actions as a paracrine, endocrine, and neurotransmitter (1). Its principal effects on the target organ are the inhibition of gastrointestinal hormone functions (2-5), as well as the inhibition of the secretion of gastrointestinal hormones themselves, such as gastrin, cholecystokinin-pancreozymin (PZ), and secretin (6-8).

Somatostatinoma, which produces somatostatin, is very frequently complicated with cholelithiasis and steatorrhea (9). In contrast with endogenous somatostatin, which shows several minutes of biological half life, SMS-201-995 (Sandostatin ${ }^{\circledR}$, hereinafter abbreviated as octreotide) is a somatostatin analogue, and has been developed and utilized as a therapeutic agent for endocrine gastrointestinal tumor (indicated for VIPoma, carcinoid, and gastrinoma in Japan). However, because it inhibits the functions of the above target organs (10) in addition to inhibiting the hormone secretion from the endocrine organs, adverse reactions develop in various gastrointestinal organs. In fact, when octreotide is used for a short period in patients with carcinoid or for a long period in patients with endocrine gastrointestinal tumor, steatorrhea is aggravated $(11,12)$. When octreotide is used even in healthy subjects with $100 \mathrm{~g}$ of fat for a short period, it causes steatorrhea (13). It is reported (12) that the decrease (observed in one-third to one-fourth of healthy subjects) of lipase activity cannot cause the steatorrhea and that the administration of pancreatic extracts during octreotide administration offers no improvement in steatorrhea.

To clarify the mechanism of this steatorrhea, we investigated pancreatic bicarbonate secretion and bile acid concentration other than lipase secretion in healthy subjects treated with octreotide since all of these are necessary for fat digestion and absorption. Also, octreotide was administered before each meal to healthy subjects with a daily intake of $60 \mathrm{~g}$ fat and changes in the fecal fat and bile acid excretions were examined.

\section{Subjects and Methods}

The subjects were 8 healthy adult males (aged $20-30$ years) who consented to participate in the test. The protocol was approved by the Institutional Human Investigation Committee

From the Third Department of Internal Medicine, Hirosaki University School of Medicine, Hirosaki

Received for publication October 12, 1993; Accepted for publication June 20, 1994

Reprint requests should be addressed to Dr. Teruo Nakamura, the Third Department of Internal Medicine, Hirosaki University School of Medicine, 5 Zaifu-cho, Hirosaki, Aomori 030 
of Hirosaki University.

Five subjects were selected at random from the 8 men, and a Dreiling-type double lumen tube was inserted into Treitz's ligament during fasting in the early morning. In the control group, physiological saline was subcutaneously (s.c) administered 30 minutes before the test, then PZ and secretin (Boots

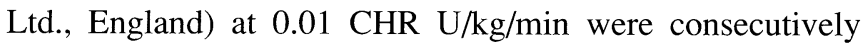
dripped, and the duodenal juice was collected every 10 minutes up to 120 minutes. In 5 cases of the octreotide group, $100 \mu \mathrm{g}$ of octreotide was s.c. administered 30 minutes before the drip administration of $\mathrm{PZ}$ and secretin and testing was performed.

The duodenal juice was assessed for the concentrations of bile acid ( $3 \alpha$-HSD, Enzybile 2, Daiichi Pure Chemicals Co., Ltd., Tokyo, Japan), bicarbonate (Natelson method) (14), and lipase (BALB, DTNB method [lipase kit S., Dainihon Pharmaceutical Co., Ltd., Osaka, Japan]). The bile acid concentration was expressed as a unit of $\mathrm{mM}$, while bicarbonate and lipase were expressed ( $\mathrm{mEq}$ and IU respectively) by the excretion at each time, multiplying by the fluid volume for 10 minutes.

Also, 5 of the 8 subjects took $2,200 \mathrm{kcal}(60 \mathrm{~g}$ of fat) and their feces was collected consecutively for 3 days before the start of the test. Following this, $100 \mu \mathrm{g}$ of octreotide was s.c. administered $30 \mathrm{~min}$ before each meal consecutively for 7 days, and the feces was collected for the last 3 days. The obtained feces was diluted with water, homogenized, and freeze-dried. To the freeze-dried feces, 23-nordeoxy-cholic acid was added as an internal standard, then hydrolysis was conducted in an autoclave $\left(120^{\circ} \mathrm{C}\right)$ for 3 hours, and after methylation and purification in an alumina column, the bile acids in the feces were analyzed as an acetyl derivative in a $1 \%$ XE- 60 column by gasliquid chromatography (GLC) (15). Meanwhile, as for the fatty acids in the feces, heneicosanoic acid was added to the new fresh stool as an internal standard, after reflux-extraction with chloroform-methanol under $\mathrm{N}_{2}$ stream. Hydrolysis and methylation followed, and analysis was conducted in a $10 \%$
EGSP column by GLC (15). The obtained amount of fatty acid was expressed as neutral fat.

Statistical analysis was made by the Mann-Whitney U-test or the paired $t$ test.

\section{Results}

\section{Changes in duodenal juice (Table 1)}

1) Concentration of bile acid

At a period of $15 \mathrm{~min}$ before administration of PZ-secretin, no significant difference was observed in the concentration of bile acid between the control and octreotide groups. However, the bile acid concentration in the duodenal juice significantly $(\mathrm{p}<0.05-\mathrm{p}<0.01)$ decreased from 10 minutes to 80 minutes in the octreotide group compared with the control group. The bile acid concentration in the octreotide group decreased to zero over a period of 50 minutes to 80 minutes in some cases. Also, the bile acid concentration fell to less than $4 \mathrm{mM}$, the critical micellar concentration (16), during the 50 minutes period from 50 minutes to 100 minutes. The minimal value of duodenal bile acid concentration was recorded at 70 minutes (100 minutes after octreotide administration). The overall sum of the bile acid concentration decreased to $53.5 \mathrm{mM}$ in the octreotide group, about one-quarter of the $191.0 \mathrm{mM}$ decrease in the control group.

\section{2) Bicarbonate output}

At a period of 15 minutes before $\mathrm{PZ}$-secretin administration, no significant difference was observed in the bicarbonate output between the control and octreotide groups. However, the bicarbonate output significantly $(p<0.05-p<0.01)$ decreased in the octreotide group during the period of 10 minutes to $120 \mathrm{~min}$ utes (except for the 100 minutes), as compared with the control group. The overall sum of the bicarbonate output decreased to $11.3 \mathrm{mEq}$ in the octreotide group, about one-quarter of the 39.9 $\mathrm{mEq}$ decrease in the control group.

Table 1. Effects of Somatostatin Analogue on Duodenal Bile Acid Concentration, Bicarbonate Output, and Lipase Output

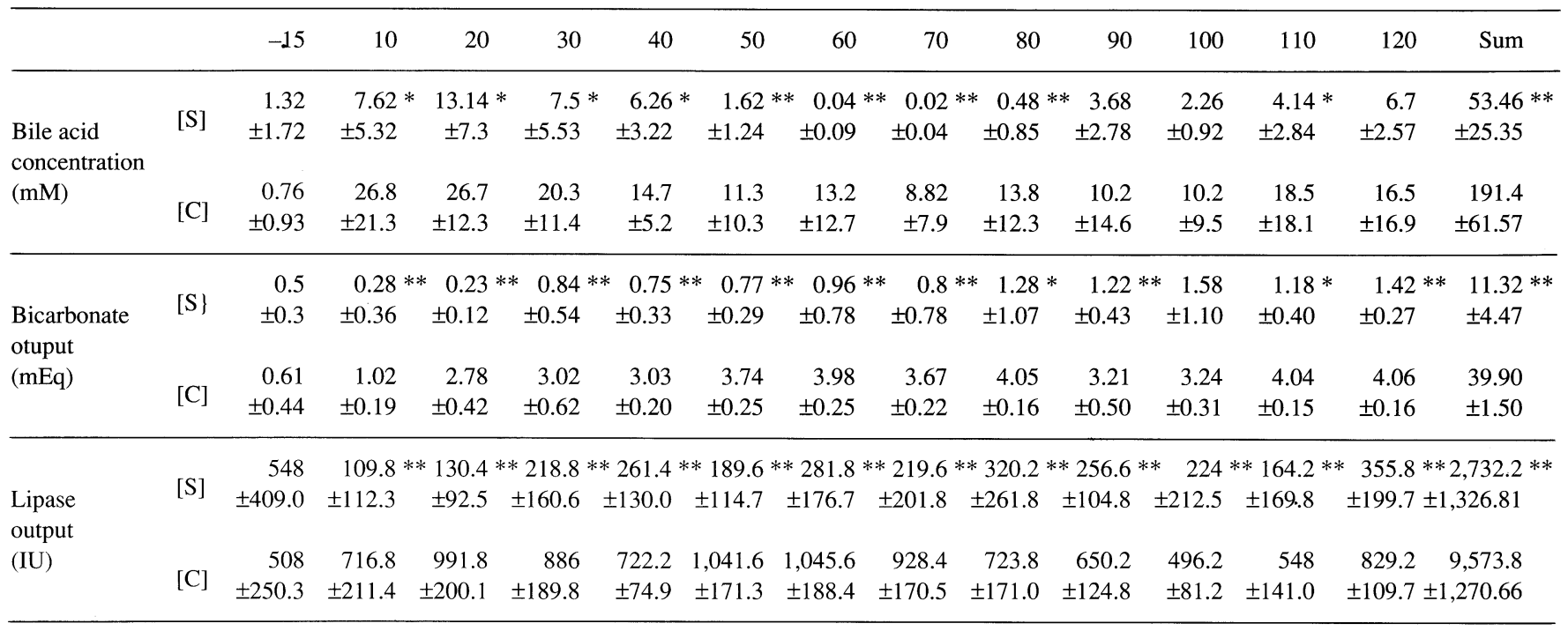

All values were expressed as mean $\pm \mathrm{SD}$. [S]: somatostatin-analogue administration group $(\mathrm{n}=5),[\mathrm{C}]$ : control group $(\mathrm{n}=5)$, *p<0.01, **p<0.05 vs. control. 
Table 2. Effects of Somatostatin Analogue on Fecal Fat and Fecal Bile Acid Excretion as Measured before and after Each Meal for 7 Days

\begin{tabular}{lcccc}
\hline Case & \multicolumn{2}{c}{$\begin{array}{c}\text { Fecal fat } \\
\text { (g/day) }\end{array}$} & \multicolumn{2}{c}{$\begin{array}{c}\text { Fecal bile acid } \\
(\mathrm{mg} / \text { day })\end{array}$} \\
\hline & Before & After & Before & After \\
\hline 1 & 0.8 & 4.3 & 233.2 & 55.2 \\
2 & 1.0 & $27.9^{\dagger}$ & 165.1 & 47.0 \\
3 & 1.5 & 5.6 & 256.0 & 60.0 \\
4 & 2.8 & 2.9 & 300.3 & 70.3 \\
5 & 1.9 & $13.1^{\dagger}$ & 212.4 & 40.3 \\
\hline Mean & 1.6 & 10.8 & 233.4 & $54.6^{*}$ \\
\pm SD & \pm 0.8 & \pm 10.4 & \pm 50.2 & \pm 11.6 \\
\hline
\end{tabular}

${ }^{\dagger}$ Steatorrhea was observed. *Significant $(\mathrm{p}<0.01)$ change as compared with the value before somatostatin administration.

Maximal inhibition of bicarbonate output was recorded at 20 minutes (that is, 50 minutes after the administration of octreotide).

\section{3) Lipase output}

At all intervals of the octreotide group, except for 15 minutes before PZ-secretin administration, the lipase output showed significant $(p<0.05-p<0.01)$ decreases in comparison with the control group. The overall sum of the lipase output in the octreotide group was 2,732.2 IU, showing a significant $(\mathrm{p}<0.01)$ decrease compared with $9,573.8 \mathrm{IU}$ in the control group. The decrease in the octreotide group was about $1 / 3$ of the control group.

Maximal inhibition of lipase output was recorded at 10 minutes (40 minutes after the octreotide administration).

\section{Excretions of fat and bile acid in feces}

As shown in Table 2, the fat excretion in the feces before administration of octreotide was $1.6 \mathrm{~g} /$ day and it increased to $10.8 \mathrm{~g} /$ day after administration. Obvious greasy stool (steatorrhea) was observed in 2 cases (case 3 and 4). On the other hand, the bile acid excretion in the feces was $233.4 \mathrm{mg} /$ day before octreotide administration and it decreased to $54.6 \mathrm{mg} /$ day, i/.e., about $1 / 4$ of the prior level, after octreotide administration. This was a significant $(\mathrm{p}<0.01)$ decrease.

\section{Discussion}

When a long-acting somatostatin analogue at a dose of $50 \mu \mathrm{g}$ is s.c. injected, its blood concentration peaks at 30 minutes, and it shows a biological half-life of 90 minutes (17).

In the present study, the times of reaching the nadir, after the administration of octreotide were different between bicarbonate and lipase output. That is, the lowest values in acinar cell and ductal cell responses to PZ-secretin were recorded at $40 \mathrm{~min}$ utes and 50 minutes after analogue administration, respectively, while the minimal bile acid concentration in the duodenum was noted at 100 minutes.

Therefore, it is conceivable that the pancreatic acinar cell and ductal cell are more sensitive to octreotide than the smooth muscles of the gallbladder. The gallbladder contraction was slower than pancreatic exocrine inhibition.

Pancreatic maldigestion and malabsorption develop when the pancreatic lipase secretion decreases to less than $10 \%$ of the normal amount (18). It is clear that pancreatic enzyme supplement by itself offers no improvement in cases of steatorrhea. Decreases in pancreatic lipase output of $1 / 3$ to $1 / 4$ observed in this study do not differ from those previously reported (10). Steatorrhea in cases where the analogue was administered cannot be explained solely by a decrease in the lipase excretion. Bile acid is essential for the digestion and absorption of fat. Specifically, bile acid forms a micella together with monoglycerides and fatty acids in the upper small intestine (19). The minimum concentration of bile acid needed for micelle formation is defined as the critical micellar concentration (abbreviated as CMC) (16). Primary biliary cirrhosis, cholestatic jaundice, liver cirrhosis, etc. which cause deficiency of biliary secretion, have been pointed out as diseases which lower the bile acid concentration in the micellar phase of the small intestine (20-24). It is estimated that the bile acid concentration in the small intestine has become lower than the CMC (16). In the present study, the bile acid concentration in the duodenal juice due to exogenous PZ-secretin stimulation became $0 \mathrm{mM}$ at a certain time after analogue administration, and it remained less than the CMC for 60 minutes. Moreover, it is noted that pancreatic bicarbonate secretion, which is an important factor in maintaining the upper intestinal $\mathrm{pH}$ during fat digestion and absorption, is reduced to about $1 / 4$ that of the control group after administration of octreotide. In fact, it has been reported (25) that bicarbonate output from pancreatic fistulas is reduced by $45 \%$ after the administration of octreotide acetate. The duodenal $\mathrm{pH}$ determinant consists mainly of gastric acid output and bicarbonate secretion from pancreas. Therefore, the reduced bicarbonate output is supposed to lower the intestinal $\mathrm{pH}$. Therefore, we may consider the possibility that a decrease in the lipase output, in addition to the decreases in bicarbonate excretion and bile acid concentration, may act contributively or synergistically, resulting in the development of fat maldigestion and malabsorption. Moreover, it has been suggested (3) that the fat absorption in the small intestine may be inhibited by the analogue, although we have not examined this possibility.

One case (case 4) showed no steatorrhea during octreotide administration. Fat digestion must have been completed before the octreotide inhibited the pancreatic and biliary functions in case of the facilitated gastric emptying. The details remain unclear, however, as we were unable to investigate the gastric emptying.

In the present study, $100 \mu \mathrm{g}$ of the analogue was s.c. injected before each meal, and consequently steatorrhea was observed. Accordingly, a method for administering less than $100 \mu \mathrm{g}$ may be worth considering in order to reduce steatorrhea. Also, as pointed out by Creutzfeldt et al (10), steatorrhea due to the analogue administration may not persist for a long time. It seems that due attention should be paid to minor adverse reactions such as steatorrhea in the beginning of analogue 


\section{NAKAMURA et al}

administration.

From the above results, we conclude that octreotide administration to healthy subjects decreases bicarbonate, lipase secretion and reduces the duodenal bile acid concentration. Consequently, it is conceivable that the synergic inhibition of biliary and pancreatic functions may cause steatorrhea during octreotide administration in humans.

\section{References}

1) Lucey MR. Endogenous somatostatin and the gut. Gut 27: 457, 1986.

2) Arnold R, Creutzfeldt W. Hemmung der pentagastrin-induzierten Säuresekretion des Magens durch Somatostatin. Dtsch Med Wochenschr 100: 1014, 1975.

3) Creutzfeldt W, Lankisch PG, Fölsch UR. Hemmung der Sekretin und Cholezystokinin-Pancreozymin-induzierten Saft und Enzymsekretion des Pankreas und der Gallenblasenkontraktion beim Menschen durch Somatostatin. Dtsch Med Wochenschr 100: 1135, 1975.

4) Krejs GJ, Browne R, Raskin P. Effect of intravenous somatostatin on jejunal absorption of glucose, amino acids, water, and electrolytes. Gastroenterology 78: 26, 1980.

5) Johansson C, Wisén O, Efendic S, Uvnäs-Wallensten K. Effects of somatostatin on gastrointestinal propagation and absorption of oral glucose in man. Digestion 22: 126, 1981.

6) Bloom $\mathrm{S}$, Moshiner $\mathrm{CH}$, Thorner $\mathrm{MO}$, et al. Inhibition of gastrin and gastric acid secretion by growth hormone release-inhibitory hormone. Lancet ii: 1106, 1974.

7) Boden G, Sivitz MC, Owen OE, Essa-KovmarN,Landor JH. Somatostatin suppresses secretin and pancreatic exocrine secretion. Science 190: 163, 1975.

8) Schlegel W, Harvey RF, Raptiss Oliver JML, Pfeiffer EE. Inhibition of cholecystokinin-pancreozymin release by somatostatin. Lancet ii: 166, 1977.

9) Christensen SE. Somatostatinoma. in: Recent Advances in Diabetes. Nattrass M, Ed. Churchill Livingstone, Edinburgh, London, Melbourne, New York, 1986, p.61.

10) Creutzfeldt W, Lembcke B, Fölsch UR, Schleser S, Koop I. Effect of somatostatin analogue (SMS 201-995, Sandostatin) on pancreatic secretion in humans. Am J Med 82 (Suppl 5B): 49, 1987.

11) Richter G, Stöckmann F, Lembcke B, Conlon JM, Creutzfeldt W. Shortterm administration of the somatostatin analogue SMS 201-995 in patients with carcinoid tumors. Scand J Gastroenterol 21 (Suppl 119): 193,
1986.

12) Stöckmann F, Richter G, Lembcke B, Conlon JM, Creutzfeldt W. Longterm treatment of patients with endocrine gastrointestinal tumors with the somatostatin analogue SMS 201-995. Scand J Gastroenterol 21 (Supp] 119): 230, 1986.

13) Lembcke B, Creutzfeldt W, Schleser $S$, Ebert R, Shaw C, Koop I. Effect of the somatostatin analogue Sandostatin (SMS 201-995) on gastrointestinal, pancreatic and biliary function and hormone release in normal men. Digestion 36: 108, 1987.

14) Natelson $S$, Menning CM. Improved methods of analysis for oxygen, carbon monoxide, and iron on fingertip blood. Clin Chem 1: 165, 1955.

15) Nakamura $T$, Imamura $K$, Abe $Y$, Miyazawa $T$, Takebe $K$, Kikuchi $H$. Mild bile acid malabsorption and normal excretion of fecal hydroxy fatty acids in patients with chronic pancreatitis. Jpn J Gastroenterol 77: 1770, 1980.

16) Badley BWD, Murphy GM, Bouchier IAD, Scherlock SD. Diminished micellar phase lipid in patients with chronic non alcoholic liver disease and steatorrhea. Gastroenterology 58: 781, 1970.

17) Kraenzlin ME, Wood SM, Neufeld M, Adrian TE, Bloom SR. Effect of long acting somatostatin-analogue, SMS 201-995, on gut hormone secretion in normal subjects. Experientia 41: 738, 1985.

18) DiMagno EP, Go VLW, Summerskill WHJ. Relations between pancreatic enzyme outputs and malabsorption in severe pancreatic insufficiency. N Engl J Med 288: 813, 1973.

19) Hofmann AF, Borgström $B$. The intraluminal phase of fat digestion in man: The lipid content of the micellar and oil phases of intestinal content obtained during fat digestion and absorption. J Clin Invest 43: 247, 1964.

20) Nakamura T, Makino I, Imamura $K$, et al. Relation between fat malabsorption and fecal bile acid excretion in patients with hepatobiliary diseases. Jpn J Gastroenterol 81: 900, 1984.

21) Miettinen TA, Siurala M. Micellar solubilization of intestinal lipids and sterols in gluten enteropathy and liver cirrhosis. Scand J Gastroenterol 6: 527, 1975.

22) Fordtran JS, Bunch F, Davis GR. Ox bile treatment of severe steatorrhea in an ilectomy-ileostomy patient. Gastroenterology 82: 564, 1982.

23) Lanspa SJ, Chan ATH, Bell JS, Go VLW, Diakson ER, DiMagno EP. Pathogenesis of steatorrhea in primary biliary cirrhosis. Hepatology $\mathbf{5}$ : 837, 1985 .

24) Salvioli G, Carati L, Lugli R. Steatorrhea in cirrhosis: Effect of ursodeoxycholic acid administration. J Int Med Res 18: 289, 1990.

25) Williams ST, Woltering EA, O'Dorisio TM, Fletcher WS. Effect of octreotide acetate on pancreatic exocrine function. Am J Surg 157: 459, 1989. 